\title{
Zirconyl Clindamycinphosphate Antibiotic Nanocarriers for Targeting Intracellular Persisting Staphylococcus aureus
}

\author{
Joachim G. Heck, ${ }^{\dagger}$ Katharina Rox, ${ }^{\ddagger}{ }^{\S}$ Heinrich Lünsdorf, ${ }^{\ddagger}$ Thorsten Lückerath, $^{\dagger}$ Nicole Klaassen, ${ }^{\dagger}$

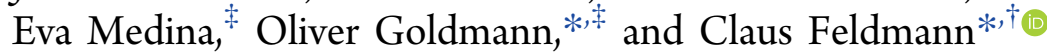 \\ ${ }^{\dagger}$ Institute of Inorganic Chemistry, Karlsruhe Institute of Technology (KIT), Engesserstrasse 15, 76131 Karlsruhe, Germany \\ ${ }^{\ddagger}$ Helmholtz-Zentrum für Infektionsforschung, Inhoffenstrasse 7, D-38124 Braunschweig, Germany \\ ${ }^{\S}$ Deutsches Zentrum für Infektionsforschung, Partner Site Hannover-Braunschweig, Inhoffenstrasse 7, D-38124 Braunschweig, \\ Germany
}

\section{Supporting Information}

ABSTRACT: $[\mathrm{ZrO}]^{2+}[\mathrm{CLP}]^{2-}$ (CLP: clindamycinphosphate) inorganic-organic hybrid nanoparticles (IOH-NPs) represent a novel strategy to treat persisting, recurrent infections with multiresistant Staphylococcus aureus. $[\mathrm{ZrO}]^{2+}[\mathrm{CLP}]^{2-}$ is prepared in water and contains the approved antibiotic with unprecedented high load ( 82 wt \% CLP per nanoparticle). The IOH-NPs result in 70-150-times higher antibiotic concentrations at difficult-to-reach infection sites, offering new options for improved drug delivery for chronic and difficult-to-treat infections.

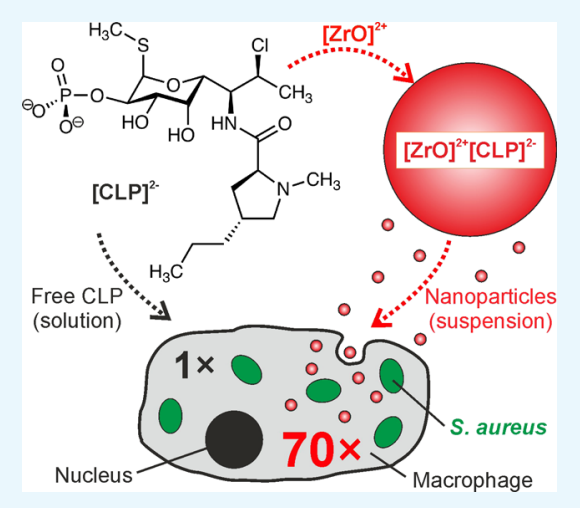

\section{INTRODUCTION}

The overuse and inappropriate application of antibiotics is well known to lead to the emergence of antibiotic resistance- and even more challenging - to an increase of multidrug resistances (MDR) among several bacterial species. ${ }^{1}$ MDR Mycobacterium tuberculosis, or Gram-negative bacteria with extended-spectrum $\beta$-lactamase production (e.g., Klebsiella pneumoniae, Pseudomonas aeruginosa, and Enterobacter species) and among Grampositive bacteria, especially Staphylococcus aureus (S. aureus), have become a major problem for the global healthcare system by increasing healthcare costs due to high morbidity and mortality rates and prolonged hospitalization. ${ }^{2,3}$

A central issue in the development of MDR bacteria is related to the fact that classical treatment strategies often lead to insufficient levels of anti-infectives in various niches of the host such as the intracellular milieu, rendering the treatment less efficient and increasing the threat that pathogens become resistant. $^{2-6} S$. aureus, for example, is known to establish intracellular infection reservoirs because of internalization and persistence in several host cells (e.g., mast cells, dendritic cells, macrophages, epithelial cells, and osteoblasts). ${ }^{3,7-11}$ Certain $S$. aureus subpopulations (small colony variants) are even well adapted to persist for long periods in the intracellular milieu, ${ }^{12-15}$ and they are associated with chronic, relapsing, and therapy-refractory infections such as osteomyelitis or cystic fibrosis. ${ }^{16-19}$

Promising concepts to conquer these problems and to restrict antimicrobial resistance relate to the development of new antimicrobial agents or-equally important-the evolution of more efficient dosage forms of conventional antibiotics for obtaining sufficient concentration levels in the intracellular milieu to guarantee bacterial eradication. ${ }^{2-6}$ Typically, the maximum concentration of antibiotics, however, is limited by solubility/availability (in blood, cells, tissue), penetration (through membranes), retention time (due to biodegradation or excretion), as well as by induced side effects. Higher concentrations within the intracellular milieu could be achieved via more efficient uptake into infected cells and tissue. In this regard, several nanoparticle-based concepts were suggested (e.g., tuberculosis treatment) ${ }^{20,21}$ that use the different uptake of nanoparticles (i.e., phagocytosis and pinocytosis) in comparison to molecular antibiotics in solution (i.e., via ion channels or passive diffusion through lipid double layers). ${ }^{22,23}$

Nanoparticle-based concepts for antibiotic delivery predominately relate to organic polymers and micelles ${ }^{24-27}$ as well as inorganic compounds (e.g., $\mathrm{SiO}_{2}, \mathrm{Fe}_{2} \mathrm{O}_{3}, \mathrm{Ag}$, and $\mathrm{Au}),^{20,21,28-34}$ in which the antibiotic is encapsulated. These concepts intrinsically have the disadvantage of comparably low drug contents (typically $<10$ wt \%) in mainly nonactive matrices as the majority material. In some cases, moreover, elaborate, multistep synthesis is needed and/or the particle size

Received: April 3, 2018

Accepted: July 13, 2018

Published: August 2, 2018 


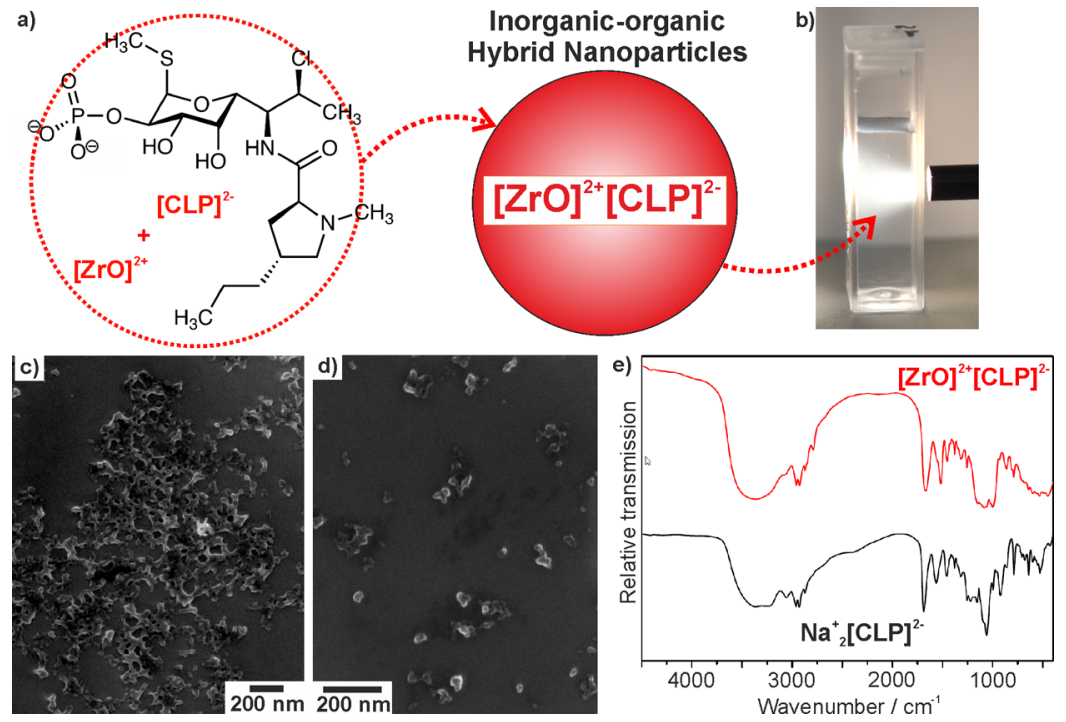

Figure 1. Scheme illustrating the water-based synthesis of $[\mathrm{ZrO}]^{2+}[\mathrm{CLP}]^{2-} \mathrm{IOH}-\mathrm{NPs}$ : (a) structure of antibiotic $[\mathrm{CLP}]^{2-}$ anion; (b) photograph of aqueous $[\mathrm{ZrO}]^{2+}[\mathrm{CLP}]^{2-}$ suspension; $(c+d)$ electron microscopy of nanoparticles; and (e) FT-IR spectra $\left[\right.$ with $\mathrm{Na}_{2}(\mathrm{CLP})$ as reference].

is too large $(>150 \mathrm{~nm})$ for what is considered as optimal for biomedical nanoparticle applications $(50-100 \mathrm{~nm}){ }^{20,21,28-34}$ All in all, nanoparticular antibacterial agents appear to have great potential to revolutionize the diagnosis and treatment of bacterial infections. ${ }^{35-40}$

To address the challenge of intracellular MDR bacteria, we here suggest saline $[\mathrm{ZrO}]^{2+}[\mathrm{CLP}]^{2-}$ inorganic-organic hybrid nanoparticles (IOH-NPs) as a novel nanocontainer concept to deliver antibiotics with extremely high concentration directly to $S$. aureus in intracellular niches. $[\mathrm{ZrO}]^{2+}[\mathrm{CLP}]^{2-}$ is an insoluble, saline compound, made in water, which contains an unprecedented high load of 82 wt \% of antibiotic [CLP $]^{2-}$ (CLP: clindamycinphosphate). CLP is a clinically approved pro-drug for the active last resort antibiotic clindamycin (CL). ${ }^{41,42}$ Both-CLP and CL-are highly bacteriostatic, bactericidal (at higher concentration), and widely used to treat staphylococcal infections-but by now only in dissolved, free form. ${ }^{41,42}$

\section{RESULTS AND DISCUSSION}

2.1. Material Synthesis and Characterization. $[\mathrm{ZrO}]^{2+}[\mathrm{CLP}]^{2-}$ was prepared by injecting an aqueous solution of $\mathrm{ZrOCl}_{2} \times 8 \mathrm{H}_{2} \mathrm{O}$ to aqueous solutions of $\mathrm{Na}_{2}$ (CLP) at $55{ }^{\circ} \mathrm{C}$ (Figure 1a). The synthesis compares to our previously presented concept of phosphate-based $\mathrm{IOH}$ N P s with a general composition $[\mathrm{ZrO}]^{2+}\left[\mathrm{R}_{\text {Function }} \mathrm{OPO}_{3}\right]^{2-}$. 33,44 Herein, the inorganic cation $[\mathrm{ZrO}]^{2+}$ and a functional organic anion $\left[\mathrm{R}_{\text {Function }} \mathrm{OPO}_{3}\right]^{2-}$ together form a saline hybrid material. $[\mathrm{ZrO}]^{2+}$ as the cation and a phosphate group as part of the organic anion guarantee for the insolubility of the IOH-NPs in water (Figure 1a). On the basis of different functional organic anions, a wide range of IOH-NPs entailing various functionalities such as fluorescence, magnetism, or drug delivery can be realized so that the $\mathrm{IOH}$ NPs become suitable for multimodal imaging and/or cancer treatment (Supporting Information: Figure S1). ${ }^{43,44}$ Here, we can expand the material concept to antibiotic nanocarriers for the first time. To obtain the saline $[\mathrm{ZrO}]^{2+}[\mathrm{CLP}]^{2-} \mathrm{IOH}-\mathrm{NPs}$ and colloidally stable suspensions, particle nucleation and particle growth have to be performed precisely (Figure 1b;
Supporting Information). ${ }^{45}[\mathrm{ZrO}]^{2+}[\mathrm{CLP}]^{2-}$ is insoluble in water and can be easily suspended in polar solvents such as water, ethanol, diethylene glycol, or biological buffers (e.g., HEPES and aqueous dextran). Slow dissolution of the $[\mathrm{ZrO}]^{2+}[\mathrm{CLP}]^{2-}$ IOH-NPs in an active metabolism-similar to CLP as conventional pro-drug in solution-results in the release of $\mathrm{CL}$ as the active drug in the presence of phosphatases. ${ }^{41,42}$

On the basis of the good availability of CL as a standard anti-infective and the low-cost aqueous synthesis, $[\mathrm{ZrO}]^{2+}[\mathrm{CLP}]^{2-} \mathrm{IOH}-\mathrm{NPs}$ can be obtained in large quantities and concentrated suspensions (up to $20 \mathrm{mg} / \mathrm{mL}$ ). Scanning electron microscopy (SEM) (Figure 1c,d) confirms the presence of spherical nanoparticles with a mean diameter of $44 \pm 11 \mathrm{~nm}$ (calculated by statistical evaluation of 100 particles). The hydrodynamic diameter (73(14) nm) obtained via dynamic light scattering is as large as the value obtained by SEM (Supporting Information: Figure S2), which can be ascribed to the high polarity of water and the resulting expanded rigid solvent shell. Moreover, the absence of any specific surface stabilizer on the as-prepared $\mathrm{IOH}-\mathrm{NPs}$ needs to be taken into account, which facilitates the synthesis and which allows avoiding any eventual toxic effect of a stabilizer. Energydispersive X-ray analysis (EDX), Fourier-transform infrared spectroscopy (FT-IR), thermogravimetry (TG), and elemental analysis (EA) validate the chemical composition of $[\mathrm{ZrO}]^{2+}[\mathrm{CLP}]^{2-}$ as a new compound. EDX and FT-IR qualitatively prove the presence of $[\mathrm{ZrO}]^{2+}$ and $[\mathrm{CLP}]^{2-}$ (Figure 1e). Quantification via total organics combustion (TG) shows a weight loss of $66 \%$ fitting well with the expectation (calcd. 68\%) (Supporting Information: Figure S3). EA data of 33.0 wt \% C, 5.6 wt \% H, 5.6 wt \% N, 4.6 wt \% S also agree with the expectation (calcd C: $35.0, \mathrm{H}: 4.6, \mathrm{~N}: 5.3$, S: $5.3 \mathrm{wt} \%)$.

2.2. Biocompatibility and Cell Uptake. Biocompatibility and cell uptake were verified by feeding $[\mathrm{ZrO}]^{2+}[\mathrm{CLP}]^{2-} \mathrm{IOH}-$ NPs to murine bone marrow derived macrophages (BMDMs) - a cell type generally showing high uptake rates of nanoparticles. ${ }^{45}$ BMDMs were grown in sterile 4-chamber slides to form confluent cell monolayers and incubated for $6 \mathrm{~h}$ in the presence of $[\mathrm{ZrO}]^{2+}[\mathrm{CLP}]^{2-} \mathrm{IOH}-\mathrm{NPs}$. Within this time 
period, numerous $[\mathrm{ZrO}]^{2+}[\mathrm{CLP}]^{2-} \mathrm{IOH}-\mathrm{NPs}$ were phagocytosed and appear within primary lysosomes ( $\mathrm{pLs}$ ) either individually or as electron dense clusters (Figure 2a,b: red
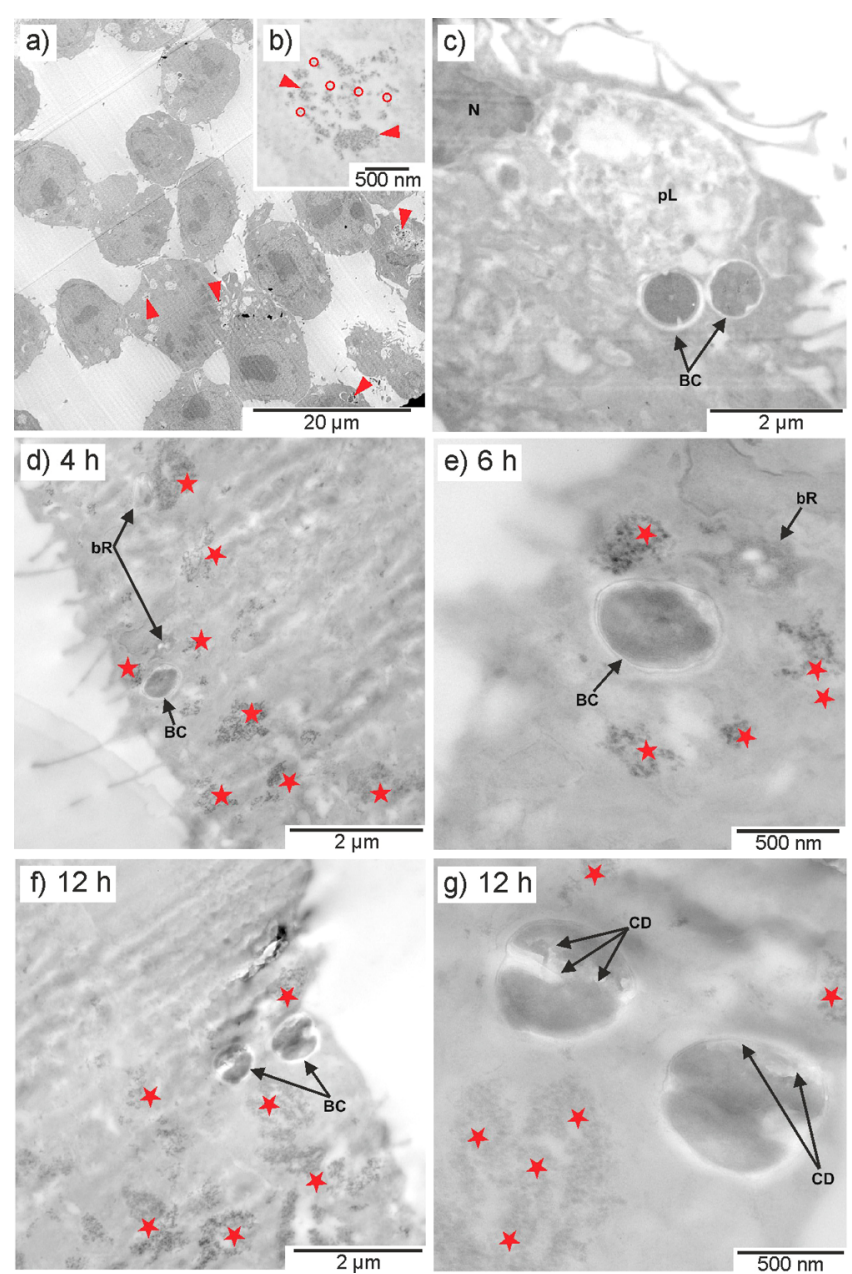

Figure 2. Electron microscopy of murine macrophages, infected with S. aureus $\mathrm{SH} 1000$ and treated with $[\mathrm{ZrO}]^{2+}[\mathrm{CLP}]^{2-}$ IOH-NPs: (a) survey of "en face"-sectioned, unstained macrophages, treated with $[\mathrm{ZrO}]^{2+}[\mathrm{CLP}]^{2-}$ for $6 \mathrm{~h}$ (red arrowheads indicate IOH-NP clusters). (b) Detailed view of IOH-NP clusters (red arrowheads) and individual IOH-NPs (red circles) within the pL. (c) Macrophage infected for $12 \mathrm{~h}$ with $S$. aureus without IOH-NPs (infection control). $(\mathrm{d}-\mathrm{g})$ Macrophages treated with $[\mathrm{ZrO}]^{2+}[\mathrm{CLP}]^{2-} 12 \mathrm{~h}$ before infection with $S$. aureus and after 4,6 , and $12 \mathrm{~h}$ of incubation ( $\mathrm{IOH}-$ $\mathrm{NP}$ clusters indicated by red stars). Indicators: $\mathrm{pL}$ : primary lysosome, $\mathrm{N}$ : nucleus, BC: bacterial cell, CD: cellular defects, bR: bacterial remnant.

circles, red arrowheads). S. aureus cells are characteristically dispersed within the cytoplasm of infected BMDMs and actively grow within the state of binary fission (Figure $2 c$ ). To study the impact of $[\mathrm{ZrO}]^{2+}[\mathrm{CLP}]^{2-}$ on the viability of intracellular S. aureus, infected BMDMs were incubated for $4 \mathrm{~h}$ (Figure 2d), $6 \mathrm{~h}$ (Figure 2e), and $12 \mathrm{~h}$ (Figure 2f,g) with $[\mathrm{ZrO}]^{2+}[\mathrm{CLP}]^{2-}$ IOH-NPs and examined by electron microscopy. Within BMDMs, individual bacterial cells (BCs) appear surrounded by clusters of $[\mathrm{ZrO}]^{2+}[\mathrm{CLP}]^{2-}$ within in close distances $<500 \mathrm{~nm}$ (Figure 2d,g: red stars). After $12 \mathrm{~h}$ of incubation with $[\mathrm{ZrO}]^{2+}[\mathrm{CLP}]^{2-}$ IOH-NPs, the BC shows electron transparencies produced by alterations within the cell wall/subcell wall regions and the plane of binary fission that is associated with an "en-gros" change in cell morphology (Figure $2 \mathrm{~g}$ ). Such cellular defects (CD: black arrows) indicate antibiotic activity and death of the BC.

To validate the presence of $[\mathrm{ZrO}]^{2+}[\mathrm{CLP}]^{2-} \mathrm{IOH}-\mathrm{NPs}$ within lysosomes, parallel electron energy-loss spectroscopy and electron spectroscopic imaging (ESI) were performed on unstained $40 \mathrm{~nm}$ ultrathin sections of uninfected and S. aureusinfected BMDMs incubated with $[\mathrm{ZrO}]^{2+}[\mathrm{CLP}]^{2-}$ IOH-NPs (Figure 3a,b; Supporting Information: Figure S4). This allows
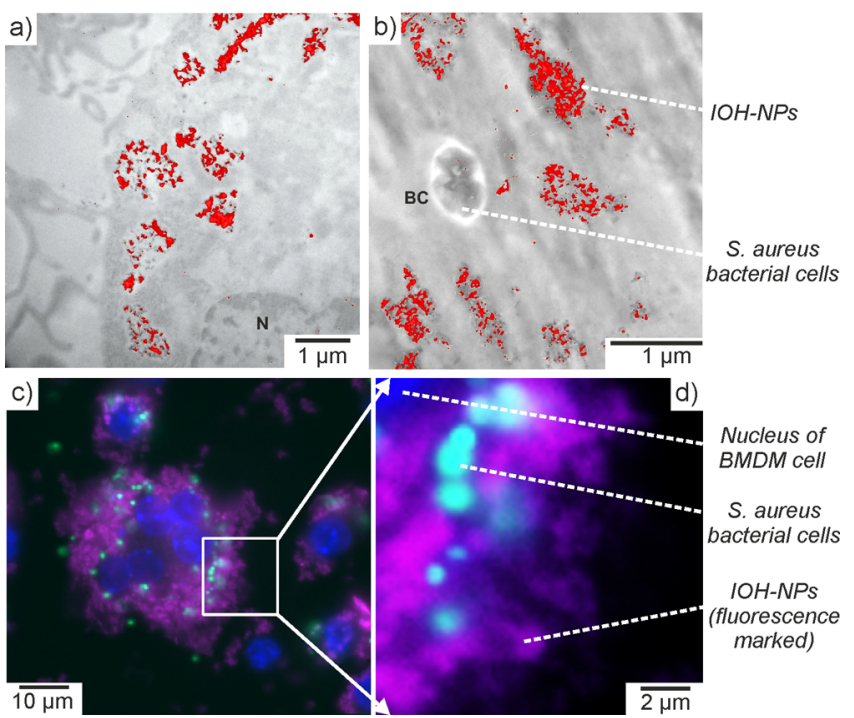

Figure 3. Localization of $[\mathrm{ZrO}]^{2+}[\mathrm{CLP}]^{2-}$ in BMDM cells: (a) $\mathrm{Zr}$ elemental map (Zr-M45 in red) of macrophage treated for $3 \mathrm{~h}$ with $[\mathrm{ZrO}]^{2+}[\mathrm{CLP}]^{2-}$ IOH-NPs and (b) after infection for $12 \mathrm{~h}$ with $S$. aureus and treated for $3 \mathrm{~h}$ with $[\mathrm{ZrO}]^{2+}[\mathrm{CLP}]^{2-} \mathrm{IOH}-\mathrm{NPs}$ (indicators: $\mathrm{BC}$ : bacterial cell, $\mathrm{N}$ : nucleus). (c,d) Fluorescence microscopy with $[\mathrm{ZrO}]^{2+}\left[(\mathrm{CLP})_{0.995}(\mathrm{DUT})_{0.005}\right]^{2-}$ IOH-NPs (purple), S. aureus (turquoise), and cellular nuclei (blue, stained with DAPI). Macrophages infected with gfp-expressing $S$. aureus strain SH1000 at an MOI of 10:1 for $1 \mathrm{~h}$ followed by co-cultivation with $[\mathrm{ZrO}]^{2+}\left[(\mathrm{CLP})_{0.995}(\mathrm{DUT})_{0.005}\right]^{2-}$ for $6 \mathrm{~h}$. Enlargement (d) shows colocalization of gfp-expressing $S$. aureus (turquoise) and $[\mathrm{ZrO}]^{2+}\left[(\mathrm{CLP})_{0.995}(\mathrm{DUT})_{0.005}\right]^{2-}$ IOH-NPs (purple).

discriminating $[\mathrm{ZrO}]^{2+}[\mathrm{CLP}]^{2-} \mathrm{IOH}-\mathrm{NPs}$ from other electron dense nanostructures such as ferritins or $\mathrm{Fe}_{2} \mathrm{O}_{3}$ particles that can be present in BMDMs. Accordingly, $\mathrm{Zr}-\mathrm{M} 45$ elemental maps show distinct $\mathrm{Zr}-\mathrm{M} 45$ intensities, congruent with $[\mathrm{ZrO}]^{2+}[\mathrm{CLP}]^{2-}$ clusters of pLs for uninfected (Figure 3a) and $S$. aureus-infected macrophages (Figure $3 \mathrm{~b}$ ), indicating the presence and high load of internalized $[\mathrm{ZrO}]^{2+}[\mathrm{CLP}]^{2-} \mathrm{IOH}-$ NPs. To validate efficient uptake and to ensure the intracellular localization of the IOH-NPs, immunofluorescence microscopy was performed using fluorescence-marked $[\mathrm{ZrO}]^{2+}\left[(\mathrm{CLP})_{0.995}(\mathrm{DUT})_{0.005}\right]^{2-}$ (DUT: dyomics-647 uridine triphosphate; Supporting Information: Figure S1) and gfpexpressing $S$. aureus bacteria (gfp: green fluorescence protein). Similar to the results of EELS and ESI, the macrophages are highly loaded with fluorescent IOH-NPs, which are found in close proximity to the intracellular bacteria (Figure $3 \mathrm{c}, \mathrm{d}$ ). The data indicate a potential localization of IOH-NPs within primary lysosomal compartments. However, further co-localization studies (e.g., using lysotracker) are needed to gain deeper insights in the molecular and cellular uptake mechanisms of IOH-NPs into the host cells. 
2.3. Antibiotic Effect. Having demonstrated that the $[\mathrm{ZrO}]^{2+}[\mathrm{CLP}]^{2-} \mathrm{IOH}-\mathrm{NPs}$ were efficiently internalized by BMDMs, their potential toxic effect on cell viability was assessed by measuring the lactate dehydrogenase (LDH) released into the supernatant by $[\mathrm{ZrO}]^{2+}[\mathrm{CLP}]^{2-}$-treated BMDMs. Generally, the release of the cytoplasmic enzyme $\mathrm{LDH}$ into the culture medium is an indication of plasma membrane disruption and cell damage. However, no significant levels of $\mathrm{LDH}$ were observed in the supernatant of $[\mathrm{ZrO}]^{2+}[\mathrm{CLP}]^{2-}$-treated and untreated BMDMs (Supporting Information: Figure S5). These results clearly indicate a lack of toxicity of $[\mathrm{ZrO}]^{2+}[\mathrm{CLP}]^{2-} \mathrm{IOH}-\mathrm{NPs}$ for BMDMs after $24 \mathrm{~h}$ of incubation.

To verify if $[\mathrm{ZrO}]^{2+}[\mathrm{CLP}]^{2-} \mathrm{IOH}-\mathrm{NPs}$ (in suspension) have an advantage over free CLP (in solution) to kill intracellular $S$. aureus, professional phagocyte BMDMs and nonprofessional phagocytic human epithelial Hep2 cells were infected with the S. aureus strain SH1000 at a multiplicity of infection of 10 bacteria per 1 eukaryotic cell for $1 \mathrm{~h}$. The infection was followed by treatment for $2 \mathrm{~h}$ with either $[\mathrm{ZrO}]^{2+}[\mathrm{CLP}]^{2-}$ (suspension) or dissolved CLP [i.e., solution of $\mathrm{Na}_{2}$ (CLP)]. Untreated infected cells were used for comparison. Cells were harvested $4 \mathrm{~h}$ (nonhatched bars) and $24 \mathrm{~h}$ (hatched bars) after infection, washed twice with sterile phosphate-buffered saline, and lysed with $\mathrm{ddH}_{2} \mathrm{O}$ for $5 \mathrm{~min}$ to release intracellular bacteria. Thereafter, the number of viable intracellular bacteria was counted after platting serial dilutions on blood agar plates. As a result, the number of viable intracellular bacteria is significantly lower in macrophages (Figure 4a) as well as in

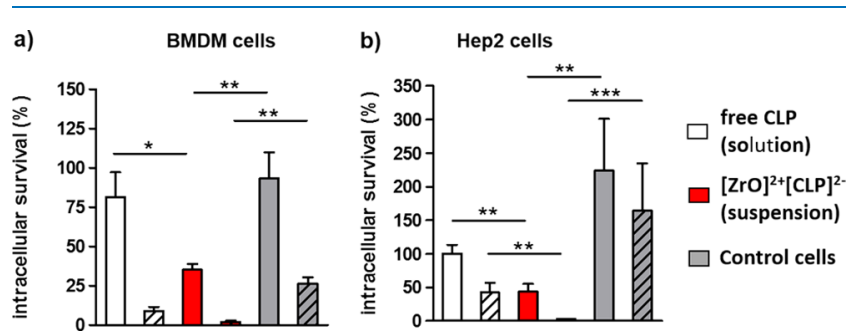

Figure 4. Intracellular survival of $S$. aureus within macrophages (BMDMs) (a) and epithelial Hep2 cells (b) 4 h (nonhatched bars) and $24 \mathrm{~h}$ (hatched bars) after infection (cells infected for $1 \mathrm{~h}$ with an MOI of 10:1; level of intracellular bacteria $1 \mathrm{~h}$ after infection referred to as $100 \%)$. Data with mean \pm SD of three experiments $(* * * p<$ $\left.0.0005, * *_{p}<0.005, * p<0.05\right)$.

Hep2 cells (Figure 4b) after treatment with $[\mathrm{ZrO}]^{2+}[\mathrm{CLP}]^{2-}$ (suspension) compared to untreated cells and cells treated with dissolved CLP (solution). Most remarkably, solutions of free CLP do not show any effect on BMDMs $4 \mathrm{~h}$ after infection (Figure 4a), whereas the IOH-NPs significantly reduce the survival rate of intracellular $S$. aureus. In non-phagocytic Hep2 cells, a significant difference between $[\mathrm{ZrO}]^{2+}[\mathrm{CLP}]^{2-}$ (suspension) and dissolved CLP was also obtained $24 \mathrm{~h}$ after infection (Figure 4b), clearly indicating the advantage of the IOH-NP drug delivery concept for cells with low bacterial killing ability. All in all, this clearly demonstrates that CL is significantly more efficient at targeting intracellular $S$. aureus when delivered as $[\mathrm{ZrO}]^{2+}[\mathrm{CLP}]^{2-}$ IOH-NPs than in the dissolved free form.

To determine if the superior bactericidal efficiency of CLloaded $[\mathrm{ZrO}]^{2+}[\mathrm{CLP}]^{2-} \mathrm{IOH}-\mathrm{NPs}$ over dissolved, free $\mathrm{CL}$ is provoked by a more efficient antibiotic penetration and retention in the intracellular milieu, the loading kinetics of either $[\mathrm{ZrO}]^{2+}[\mathrm{CLP}]^{2-}$ IOH-NPs (suspension) or free CL (solution) into eukaryotic cells was analyzed in BMDMs. Hence, BMDMs were incubated with $[\mathrm{ZrO}]^{2+}[\mathrm{CLP}]^{2-} \mathrm{IOH}-$ NPs, dissolved CLP (Figure 5) and dissolved CL hydro-
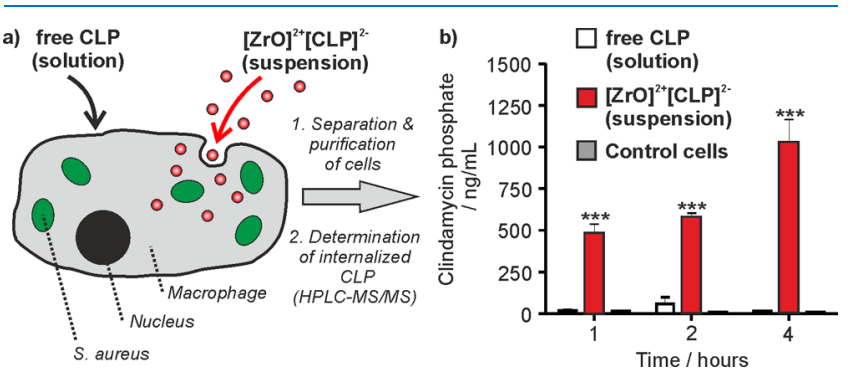

Figure 5. Intracellular CL levels within macrophages 1,2 , and $4 \mathrm{~h}$ after co-cultivation with $[\mathrm{ZrO}]^{2+}[\mathrm{CLP}]^{2-}$ IOH-NPs and dissolved CLP at identical concentrations $(50 \mu \mathrm{g} \mathrm{CLP} / \mathrm{mL})$ : (a) illustration of uptake and cell treatment; (b) internalized CL after treatment with dissolved CLP (white bars), $[\mathrm{ZrO}]^{2+}[\mathrm{CLP}]^{2-}$ (red bars), lysates of untreated cells (negative control, gray bars). Data measured by HPLC-MS/MS; mean \pm SD of triplicate samples $(* * * p<0.001)$.

chloride (CL, Supporting Information: Figure S6) for 1, 2, and $4 \mathrm{~h}$. The amount of intracellular CL was determined in BMDM lysates by high-performance liquid chromatography (HPLC)mass spectrometry (MS)/MS (Supporting Information) to determine the intracellular CL levels (Figure 5; Supporting Information: Figure S6).

As a result, the internalized CL concentration in macrophages turned out to be 70-times higher after $1 \mathrm{~h}$ of incubation when treated with $[\mathrm{ZrO}]^{2+}[\mathrm{CLP}]^{2-}$ suspensions in comparison to CLP and CL in solution (Figure 5b; Supporting Information: Figure S6, Tables S1, and S2). After $4 \mathrm{~h}$, the internalized CL concentration increases even further and is about 150 -times higher after treatment with $[\mathrm{ZrO}]^{2+}[\mathrm{CLP}]^{2-}$ suspensions (Figure 5b; Supporting Information: Figure S6, Tables S1, and S2). The intracellular levels of CLP reached $1.027 \mu \mathrm{g}$ per $\mathrm{mL}$ in macrophages incubated up to $4 \mathrm{~h}$ with the IOH-NPs (suspension). This concentration exceeds the minimal inhibitory concentration of CLP, which was determined as $<0.625 \mu \mathrm{g}$ per $\mathrm{mL}$ (Supporting Information: Figure S7). In contrast to the IOH-NP suspensions, the concentration of intracellular CLP after co-cultivation of cells with dissolved CLP remained in the subinhibitory range $<0.02$ $\mu \mathrm{g}$ per $\mathrm{mL}$. The significantly higher CLP levels reached via the IOH-NP treatment, therefore, is highly promising to address and eventually to solve the challenges related to MDR formation.

The remarkable increase of CLP uptake using IOH-NPs can be attributed to a more efficient uptake of the IOH-NPs by cellular processes such as phago-/pinocytosis and the active acquisition of the IOH-NPs as a phosphate source. ${ }^{43,44,46,47}$ These findings coincide with the efficient uptake and the intracellular localization of the $[\mathrm{ZrO}]^{2+}[\mathrm{CLP}]^{2-} \mathrm{IOH}-\mathrm{NPs}$ as shown by EELS, ESI (Figure 3a,b), and immunofluorescence microscopy (Figure $3 \mathrm{c}, \mathrm{d}$ ). The uptake of $[\mathrm{ZrO}]^{2+}[\mathrm{CLP}]^{2-}$ IOH-NPs in BMDMs, finally, shows clear time and concentration dependency (Supporting Information: Figures S8 and S9). The extremely high uptake of $[\mathrm{ZrO}]^{2+}[\mathrm{CLP}]^{2-}$ by BMDMs can become even more interesting because macrophages can abandon the blood system to attack $S$. aureus at difficult-to-reach niches of the host. ${ }^{48}$ 


\section{CONCLUSIONS}

In sum, $[\mathrm{ZrO}]^{2+}[\mathrm{CLP}]^{2-}$ IOH-NPs represent a novel nanoparticle-based strategy to treat persisting and recurrent $S$. aureus-caused infections. $[\mathrm{ZrO}]^{2+}[\mathrm{CLP}]^{2-}$ contains an unprecedented high amount ( $82 \mathrm{wt} \%$ ) of clinically approved CLP and shows high uptake at low toxicity. Most interestingly, the IOH-NP suspensions allow 70-150-times higher drug concentration (after 1-4 $\mathrm{h}$ of incubation) than the free drug in solution at difficult-to-reach intracellular infection sites. This offers unique options for improved drug delivery to eradicate intracellular bacterial reservoirs during chronic and difficult-totreat infections. Because macrophages are not limited to the blood system, they can-after loading with $[\mathrm{ZrO}]^{2+}[\mathrm{CLP}]^{2-}$ IOH-NPs-also attack multiresistant bacteria in various difficult-to-reach niches of the host with the anti-infective in very high concentrations. In principle, the material concept and delivery strategy can be also transferred to other antibiotics as well as to treat other multiresistant bacteria including the relevant species of Klebsiella, Pseudomonas, or Enterobacter.

\section{EXPERIMENTAL SECTION}

4.1. Synthesis of $\left[\mathrm{ZrO}^{2+}[\mathrm{CLP}]^{2-} \mathrm{IOH}-\mathrm{NPs} . \mathrm{Na}_{2}(\mathrm{CLP})\right.$ $(25 \mathrm{mg}$, Aldrich, 95.7\%) was dissolved in water $(50 \mathrm{~mL})$. The $\mathrm{pH}$ of this solution was adjusted to 7.0 upon the addition of diluted $\mathrm{NaOH}(140 \mu \mathrm{L}, 0.5 \mathrm{M})$. Thereafter, an aqueous solution $(5 \mathrm{~mL})$ of $\mathrm{ZrOCl}_{2} \times 8 \mathrm{H}_{2} \mathrm{O}(4.25 \mathrm{mg}$, Aldrich, 99\%) was injected. After 2 min of intense stirring, the nanoparticles were separated via centrifugation $(25000 \mathrm{rpm}, 15 \mathrm{~min})$. To remove all remaining salts, the colorless $[\mathrm{ZrO}]^{2+}[\mathrm{CLP}]^{2-}$ was resuspended in and centrifuged from $\mathrm{H}_{2} \mathrm{O}$ three times. Subsequent to redispersion, highly stable colloidal suspension in water can be obtained (Figure 1b).

\section{ASSOCIATED CONTENT}

\section{(5) Supporting Information}

The Supporting Information is available free of charge on the ACS Publications website at DOI: 10.1021/acsomega.8b00637.

Details regarding analytical techniques for material characterization, synthesis of $[\mathrm{ZrO}]^{2+}[\mathrm{CLP}]^{2-}$ and fluorescence-marked $[\mathrm{ZrO}]^{2+}\left[(\mathrm{CLP})_{0.95}(\mathrm{DUT})_{0.05}\right]^{2-}$ IOH-NPs, material characterization, and biological studies (PDF)

\section{AUTHOR INFORMATION}

\section{Corresponding Authors}

*E-mail: oliver.goldmann@helmholtz-hzi.de (O.G.).

*E-mail: claus.feldmann@kit.edu (C.F.)

\section{ORCID $\odot$}

Claus Feldmann: 0000-0003-2426-9461

Notes

The authors declare no competing financial interest.

\section{ACKNOWLEDGMENTS}

J.G.H. and C.F. thank the Deutsche Forschungsgemeinschaft (DFG) for funding of equipment. K.R. and O.G. thank Sabine Lehne and Janine Schreiber for excellent technical assistance.

\section{REFERENCES}

(1) World Health Organization (WHO). Global Health Report, 2016, ISBN 9789241564809.
(2) Fisher, R. A.; Gollan, B.; Helaine, S. Persistent bacterial infections and persister cells. Nat. Rev. Microbiol. 2017, 15, 453-464.

(3) Medina, E.; Pieper, D. H. Tackling Threats and Future Problems of Multidrug-Resistant Bacteria. How to Overcome the Antibiotic Crisis; Current Topics in Microbiology and Immunology; Springer, 2016; Vol. 398, pp 3-33.

(4) Chellat, M. F.; Raguž, L.; Riedl, R. Targeting Antibiotic Resistance. Angew. Chem., Int. Ed. 2016, 55, 6600-6626.

(5) Tong, S. Y. C.; Davis, J. S.; Eichenberger, E.; Holland, T. L.; Fowler, V. G. Staphylococcus aureus Infections: Epidemiology, Pathophysiology, Clinical Manifestations, and Management. Clin. Microbiol. Rev. 2015, 28, 603-661.

(6) Foster, T. J.; Geoghegan, J. A.; Ganesh, V. K.; Höö, M. Adhesion, invasion and evasion: the many functions of the surface proteins of Staphylococcus aureus. Nat. Rev. Microbiol. 2014, 12, 4962.

(7) Abel, J.; Goldmann, O.; Ziegler, C.; Höltje, C.; Smeltzer, M. S.; Cheung, A. L.; Bruhn, D.; Rohde, M.; Medina, E. Staphylococcus aureus Evades the Extracellular Antimicrobial Activity of Mast Cells by Promoting Its Own Uptake. J. Innate Immun. 2011, 3, 495-507.

(8) Schindler, D.; Gutierrez, M. G.; Beineke, A.; Rauter, Y.; Rohde, M.; Foster, S.; Goldmann, O.; Medina, E. Dendritic Cells Are Central Coordinators of the Host Immune Response to Staphylococcus aureus Bloodstream Infection. Am. J. Pathol. 2012, 181, 1327-1337.

(9) Surewaard, B. G. J.; Deniset, J. F.; Zemp, F. J.; Amrein, M.; Otto, M.; Conly, J.; Omri, A.; Yates, R. M.; Kubes, P. Identification and Treatment of the Staphylococcus aureus Reservoir in vivo. J. Exp. Med. 2016, 213, 1141-1151.

(10) Löffler, B.; Tuchscherr, L.; Niemann, S.; Peters, G. Staphylococcus aureus Persistence in Non-professional Phagocytes. Int. J. Med. Microbiol. 2014, 304, 170-176.

(11) Goldmann, O.; Tuchscherr, L.; Rohde, M.; Medina, E. $\alpha$ Hemolysin Enhances Staphylococcus aureus Internalization and Survival Within Mast Cells by Modulating the Expression of $\beta 1$ Integrin. Cell. Microbiol. 2016, 18, 807-819.

(12) Balwit, J. M.; Langevelde, P. V.; Vann, J. M.; Proctor, R. A. Gentamicin-Resistant Menadione and Hemin Auxotrophic Staphylococcus aureus Persist within Cultured Endothelial Cells. J. Infect. Dis. 1994, 170, 1033-1037.

(13) Grosz, M.; Kolter, J.; Paprotka, K.; Winkler, A.-C.; Schäfer, D.; Chatterjee, S. S.; Geiger, T.; Wolz, C.; Ohlsen, K.; Otto, M.; Rudel, T.; Sinha, B.; Fraunholz, M. Cytoplasmic Replication of Staphylococcus aureus upon Phagosomal Escape Triggered by Phenolsoluble Modulin $\alpha$. Cell. Microbiol. 2014, 16, 451-465.

(14) Fraunholz, M.; Sinha, B. Intracellular Staphylococcus aureus: Live-in and Let Die. Front. Cell. Infect. Microbiol. 2012, 2, 43.

(15) Sinha, B.; Fraunholz, M. Staphylococcus aureus Host Cell Invasion and Post-invasion Events. Int. J. Med. Microbiol. 2010, 300, $170-175$.

(16) Proctor, R. A.; von Eiff, C.; Kahl, B. C.; Becker, K.; McNamara, P.; Herrmann, M.; Peters, G. Small Colony Variants: a Pathogenic form of Bacteria that Facilitates Persistent and Recurrent Infections (Review). Nat. Rev. Microbiol. 2006, 4, 295-305.

(17) Sendi, P.; Rohrbach, M.; Graber, P.; Frei, R.; Ochsner, P. E.; Zimmerli, W. Staphylococcus aureus Small Colony Variants in Prosthetic Joint Infection. Clin. Infect. Dis. 2006, 43, 961-967.

(18) Kahl, B.; Herrmann, M.; Everding, A. S.; Koch, H. G.; Becker, K.; Harms, E.; Proctor, R. A.; Peters, G. Persistent Infection with Small Colony Variant Strains of Staphylococcus aureus in Patients with Cystic Fibrosis. J. Infect. Dis. 1998, 177, 1023-1029.

(19) Tuchscherr, L.; Heitmann, V.; Hussain, M.; Viemann, D.; Roth, J.; von Eiff, C.; Peters, G.; Becker, K.; Löffler, B. Staphylococcus aureus Small-Colony Variants are Adapted Phenotypes for Intracellular Persistence. J. Infect. Dis. 2010, 202, 1031-1040.

(20) Herman, A.; Herman, A. P. Nanoparticles as Antimicrobial Agents: Their Toxicity and Mechanisms of Action. J. Nanosci. Nanotechnol. 2014, 14, 946-957.

(21) Leidinger, P.; Treptow, J.; Hagens, K.; Eich, J.; Zehethofer, N.; Schwudke, D.; Oehlmann, W.; Lünsdorf, H.; Goldmann, O.; Schaible, 
U. E.; Dittmar, K. E.; Feldmann, C. Isoniazid@Fe2O3 Nanocontainers and Their Antibacterial Effect on Tuberculosis Mycobacteria. Angew. Chem., Int. Ed. 2015, 54, 12597-12601.

(22) Kafshgari, M. H.; Harding, F. J.; Voelcker, N. H. Insights into Cellular Uptake of Nanoparticles (Review). Curr. Drug Delivery 2015, 12, 63-77.

(23) Ding, H.-M.; Ma, Y.-Q. Theoretical and Computational Investigations of Nanoparticle-Biomembrane Interactions in Cellular Delivery (Review). Small 2015, 11, 1055-1071.

(24) Liu, Y.; van der Mei, H. C.; Zhao, B.; Zhai, Y.; Cheng, T.; Li, Y.; Zhang, Z.; Busscher, H. J.; Ren, Y.; Shi, L. Eradication of Multidrug-Resistant Staphylococcal Infections by Light-Activatable Micellar Nanocarriers in a Murine Model. Adv. Funct. Mater. 2017, 27, 1701974.

(25) Thiyagarajan, D.; Das, G.; Ramesh, A. Amphiphilic Cargoloaded Nanocarrier Enhances Antibiotic Uptake and Perturbs Efflux: Effective Synergy for Mitigation of Methicillin-resistant Staphylococcus aureus. ChemMedChem 2017, 12, 1125-1132.

(26) Takahashi, C.; Saito, S.; Suda, A.; Ogawa, N.; Kawashima, Y.; Yamamoto, H. Antibacterial activities of polymeric poly(DL-lactideco-glycolide) Nanoparticles and Soluplus Micelles Against Staphylococcus Epidermidis Biofilm and Their Characterization. RSC Adv. 2015, 5, 71709-71717.

(27) Díez-Martínez, R.; García-Fernández, E.; Manzano, M.; Martínez, Á.; Domenech, M.; Vallet-Regí, M.; García, P. Auranofinloaded Nanoparticles as a New Therapeutic Tool to Fight Streptococcal Infections. Sci. Rep. 2016, 6, 19525.

(28) Kwon, E. J.; Skalak, M.; Bertucci, A.; Braun, G.; Ricci, F.; Ruoslahti, E.; Sailor, M. J.; Bhatia, S. N. Porous Silicon Nanoparticle Delivery of Tandem Peptide Anti-infectives for the Treatment of Pseudomonas aeruginosa Lung Infections. Adv. Mater. 2017, 29, 1701527.

(29) Geilich, B. M.; Gelfat, I.; Sridhar, S.; van de Ven, A. L.; Webster, T. J. Superparamagnetic Iron Oxide-encapsulating Polymersome Nanocarriers for Biofilm Eradication. Biomaterials 2017, 119, $78-85$.

(30) Ruehle, B.; Clemens, D. L.; Lee, B.-Y.; Horwitz, M. A.; Zink, J. I. A Pathogen-Specific Cargo Delivery Platform Based on Mesoporous Silica Nanoparticles. J. Am. Chem. Soc. 2017, 139, 6663-6668.

(31) Qadri, S.; Haik, Y.; Mensah-Brown, E.; Bashir, G.; FernandezCabezudo, M. J.; al-Ramadi, B. K. Metallic Nanoparticles to Eradicate Bacterial Bone Infection. Nanomedicine 2017, 13, 2241-2250.

(32) Thirumurugan, G.; Seshagiri Rao, J. V. L. N.; Dhanaraju, M. D. Elucidating Pharmacodynamic Interaction of Silver Nanoparticle Topical Deliverable Antibiotics. Sci. Rep. 2016, 6, 29982.

(33) Kim, T.; Braun, G. B.; She, Z.-g.; Hussain, S.; Ruoslahti, E.; Sailor, M. J. Composite Porous Silicon-Silver Nanoparticles as Theranostic Antibacterial Agents. ACS Appl. Mater. Interfaces 2016, 8, 30449-30457.

(34) Wang, Y.; Wan, J.; Miron, R. J.; Zhao, Y.; Zhang, Y. Antibacterial Properties and Mechanisms of Gold-silver Nanocages. Nanoscale 2016, 8, 11143-11152.

(35) Li, L.-L.; Wang, H. Infection-targeted bactericidal nanoparticles. Nat. Biomed. Eng. 2018, 2, 56-57.

(36) Hussain, S.; Joo, J.; Kang, J.; Kim, B.; Braun, G. B.; She, Z.-G.; Kim, D.; Mann, A. P.; Mölder, T.; Teesalu, T.; Carnazza, S.; Guglielmino, S.; Sailor, M. J.; Ruoslahti, E. Antibiotic-loaded Nanoparticles Targeted to the Site of Infection Enhance Antibacterial Efficacy (Review). Nat. Biomed. Eng. 2018, 2, 95-103.

(37) Zaidi, S.; Misba, L.; Khan, A. U. Nano-therapeutics: A Revolution in Infection Control in Post Antibiotic Era (Review). Nanomedicine 2017, 13, 2281-2301.

(38) Hammond, P. T. Nano Tools Pave the Way to New Solutions in Infectious Disease. ACS Infect. Dis. 2017, 3, 554-558.

(39) Zazo, H.; Colino, C. I.; Lanao, J. M. Current Applications of Nanoparticles in Infectious Diseases (Review). J. Controlled Release 2016, 224, 86-102.
(40) Miller, K. P.; Wang, L.; Benicewicz, B. C.; Decho, A. W. Inorganic Nanoparticles Engineered to Attack Bacteria (Review). Chem. Soc. Rev. 2015, 44, 7787-7807.

(41) Azeh, I.; Gerber, J.; Wellmer, A.; Wellhausen, M.; Koenig, B.; Eiffert, H.; Nau, R. Protein Synthesis Inhibiting Clindamycin Improves Outcome in a Mouse Model of Staphylococcus aureus Sepsis Compared with the Cell Wall Active Ceftriaxone. Crit. Care Med. 2002, 30, 1560-1564.

(42) Reeves, D. S.; Holt, H. A.; Phillips, I.; King, A.; Miles, R. S.; Paton, R.; Wise, R.; Andrews, J. M. Activity of Clindamycin Against Staphylococcus aureus and Staphylococcus epidermidis from four UK Centres. J. Antimicrob. Chemother. 1991, 27, 469-474.

(43) Heck, J. G.; Napp, J.; Simonato, S.; Möllmer, J.; Lange, M.; Reichardt, H. R.; Staudt, R.; Alves, F.; Feldmann, C. Multifunctional Phosphate-based Inorganic-Organic Hybrid Nanoparticles. J. Am. Chem. Soc. 2015, 137, 7329-7336.

(44) Poß, M.; Tower, R. J.; Napp, J.; Appold, L. C.; Lammers, T.; Alves, F.; Glüer, C.-C.; Boretius, S.; Feldmann, C. Multimodal $[\mathrm{GdO}]^{+}[\mathrm{ICG}]^{-}$Nanoparticles for Optical, Photoacoustic, and Magnetic Resonance Imaging. Chem. Mater. 2017, 29, 3547-3554.

(45) Gottstein, C.; Wu, G.; Wong, B. J.; Zasadzinski, J. A. Precise Quantification of Nanoparticle Internalization. ACS Nano 2013, 7, 4933-4945.

(46) Zhang, S.; Gao, H.; Bao, B. Physical Principles of Nanoparticle Cellular Endocytosis (Review). ACS Nano 2015, 9, 8655-8671.

(47) Ding, H. M.; Ma, Y.-Q. Theoretical and Computational Investigations of Nanoparticle-Biomembrane Interactions in Cellular Delivery (Review). Small 2015, 11, 1055-1071.

(48) Miller, M. A.; Zheng, Y.-R.; Gadde, S.; Pfirschke, C.; Zope, H.; Engblom, C.; Kohler, R. H.; Iwamoto, Y.; Yang, K. S.; Askevold, B.; Kolishetti, N.; Pittet, M.; Lippard, S. J.; Farokhzad, O. C.; Weissleder, R. Tumour-associated Macrophages Act as a Slow-release Reservoir of Nano-therapeutic Pt(IV) Pro-drug. Nat. Commun. 2015, 6, 8692. 